\title{
Nurses' Knowledge Levels about Port Catheter Care (POCATH Study): a study of the palliative care working committee of the Turkish Oncology Group (TOG)
}

\author{
Ali Alkan', Turgut Kaçan ${ }^{2}$, Nilüfer Avcı ${ }^{3}$, Ibrahim Türker ${ }^{4}$, Selen Baloğlu Kaçan ${ }^{5}$, Arzu Ergen ${ }^{6}$, Arzu Yaşar ${ }^{7}$, \\ Özgür Tanrıverdi ${ }^{8}$, Serdar Turhal ${ }^{9}$, Filiz Çay Şenler
}

${ }^{1}$ Osmaniye Public Hospital, Medical Oncology, Osmaniye, Turkey ${ }^{2}$ Cumhuriyet University School of Medicine, Department of Medical Oncology, Sivas, Turkey ${ }^{3}$ Balıkesir State Hospital, Department of Medical Oncology, Balıkesir, Turkey ${ }^{4}$ Dr. Abdurrahman Yurtaslan Oncology Training and Research Hospital, Department of Medical Oncology, Ankara, Turkey

${ }^{5}$ Sivas Numune Hospital, Department of Internal Medicine, Sivas, Turkey ${ }^{6}$ Cerrahpasa University School of Medicine, Department of Radiation Oncology, Istanbul, Turkey

${ }^{7}$ Ankara University School of Medicine, Department of Medical Oncology,

Ankara, Turkey

${ }^{8}$ Muğla Sitkı Koçman University, School of Medicine, Department of Medical Oncology, Muğla, Turkey

${ }^{9}$ Anatolian Health Center Hospital, Department of Medical Oncology, Kocaeli, Turkey

Ali Alkan (Corresponding author) Osmaniye Public Hospital, Medical Oncology, Osmaniye, Turkey Email: alkanali@yahoo.com
Received: 11 May 2017 Accepted: 30 June 2017 DOI: $10.5799 /$ jcei.333384

\section{A B S T R A C T}

Objective: The purpose of this study is to investigate nurses' levels of knowledge about port catheters (PCs), define factors effecting them and to define the subjects in which more education strategies should be developed.

Patients and Methods: A descriptive, cross-sectional study was carried out in cancer centers in Turkey. Participants were evaluated with structured questionnaires to assess the levels of knowledge about PCs and management strategies of PC related complications. The questions were designed to evaluate their knowledge in different subscales.

Results: 363 nurses in 7 cancer centers in 4 different cities in Turkey participated in the study. While 147 (40.5\%) nurses had a more than 10 years of experience, 13.8\% of them had a less than 1 year of job experience in oncology. Knowledge about "Port catheter usage and complications" and "difficulties while using PC" was worse than other subscales. The effects of the job experience on knowledge showed a negative correlation between them $(r=-168, p=$ 0.001). In addition, participants with an experience of more than 10 years have worse scores when compared with others ( $27.2 \pm 11.4$ vs. $30.6 \pm 9.4, P=0.003)$. There was no significant difference between nurses working in a university hospital and public hospital (28.5 \pm 10.9 vs. 30.4 $\pm 10.4, P=0.086)$.

Conclusion: The study concluded that experience in the field is negatively correlated with knowledge about PCs. Nurses actively caring PCs should be routinely updated, especially about complications of PCs and management strategies of them.

Key Words: Nurse, knowledge level, port catheters, port catheter care

\section{INTRODUCTION}

Cancer is still one of the leading causes of death. Fortunately, with the ongoing developments in oncology, the survival of cancer patients is improving. Health care workers caring for cancer patients have more focused on supportive care and palliative care of these patients. Nurses are essential elements of oncology team. They are primarily responsible for ensuring that patients receive chemotherapy safely and providing the effective self-management support required enabling patients to cope both physically and psychologically with their treatments $[1,2]$.

Intravenous therapy is an important component of modern medicine and nursing. While the peripheral IV cannula was the only device available in the past, today there are short-, intermediate-, and long-term central venous catheters (such as implantable port catheters) available $[3,4]$. These devices have provided a great degree of convenience to cancer patients. Each device can be used to administer medications such as fluids, total parenteral nutrition, and chemotherapy. Patients can be treated with these devices as outpatients. Therefore, ongoing contact between patients, clinicians, and nurses plays a critical role in managing short- or long-term complications. Furthermore, nurses, have a major role to play in providing ongoing, high-quality care to patients $[3,5]$.

In the last decade, cancer patients especially treated with long infusional therapies and having 
difficulties with a peripheral intravenous line have treated with port catheters (PCs). PCs are not only used for administration of chemotherapy, parenteral nutrition, and other intravenous therapies, but they also improve the patients' quality of life by reducing the need for repeated peripheral venipunctures [6]. There are some inevitable acute and chronic complications of PCs. Deep vein thrombosis in upper extremity, occlusion of PCs and catheter related infections are the most common complications. Although symtomatic deep vein thrombosis occur in less than 4 to $8 \%$ of cases and catheter infections have a incidence of 0.2 per 1,000 catheter-days, early detection and management of complications are crucial $[7,8]$. Nurses who care cancer patients must have sufficient amounts knowledge about PCs and should be equipped to manage the complications of PCs (9). The purpose of this study is to investigate the nurses' knowledge level about PCs in Turkey, The purpose of this study is to investigate nurses' levels of knowledge about PCs, define factors effecting them and to define the subjects in which more education strategies should be developed.

\section{PATIENTS AND METHODS}

Nurses actively caring for cancer patients in Turkey were included. The study was performed in 7 different centers in Sivas, Ankara, Kocaeli, İstanbul and Balıkesir. The study was held in accordance with the ethical standards. The nurses were invited to fill the questionnaire. The study was performed between January 2015 and December 2015. A questionnaire was formed to evaluate the nurses' level of knowledge about PCs. The questionnaire consisted of 74 questions. The details about cancer center, job experience were recorded. The rest of the questionnaire consisted of 14 subscales in which there were 5 questions (Table 1). In each subscale, there were statements and participants were asked to select the best answer. The answers were defined as "I agree", "I disagree", "Not sure" and "I have no idea". One correct answer was scored as 1 point for each subscale. The answers were scored according to correct "I agree" or "I disagree" answers. The other answers were accepted as wrong. The scores of each subscale range between $0-5$ and the total score range between $0-70$. The original questionnaire is present as a supplementary material.

\section{Statistical Analysis}

To determine the differences among three or more subscales, the Kruskal-Wallis test was used. The Iman-Conover test was used in addition to determine the varieties if there were significant differences among the subscale or subscales according to result of the Kruskal-Wallis test. The analysis of numeric or ordinal variables were performed by Pearson bivariate correlations. All analyses were performed using SPSS 17.0 for Windows (IBM Corp., Armonk, NY). $P$ value of less than 0.05 was considered as statistically significant.

Table 1. Subscales titles of the questionnaire

\begin{tabular}{|c|c|}
\hline Su & Definition \\
\hline 1 & General opinions and ideas about port catheters \\
\hline 2 & Feedback on the usage of port catheters \\
\hline 3 & Previous experience with port catheter care \\
\hline 4 & Port catheter complications \\
\hline 5 & Thoughts about port catheter education \\
\hline 6 & Medications administered to patients via PC \\
\hline 7 & Port catheter infections \\
\hline 8 & Port catheter thrombosis and port catheter care \\
\hline 9 & Technique to use the PC \\
\hline 10 & Port catheter usage and complications \\
\hline 11 & Difficulties while using PC \\
\hline 12 & Thoughts about the ideal port training \\
\hline 13 & Prevention of PCs dysfunction \\
\hline 14 & Preparation of heparin lock \\
\hline
\end{tabular}

Table 2. The scores in different subscales

\begin{tabular}{|c|c|c|c|c|c|}
\hline & $\leq 1$ year $(n=49)$ & 1.1 to 5.0 years $(n=89)$ & 5.1 to 10 years $(n=75)$ & $>10$ years $(n=147)$ & Total $(n=360)$ \\
\hline Subscale 1 & $3.51 \pm 1.24$ & $3.57 \pm 1.01$ & $2.26 \pm 1.18$ & $3.17 \pm 1.37$ & $3.33 \pm 1.24$ \\
\hline Subscale 2 & $2.10 \pm 1.10$ & $1.65 \pm 0.90$ & $1.65 \pm 0.93$ & $1.52 \pm .0 .98$ & $1.66 \pm 0.98$ \\
\hline Subscale 4 & $2.65 \pm 1.15$ & $2.21 \pm 1.12$ & $2.24 \pm 1.03$ & $2.15 \pm 1.23$ & $2.25 \pm 1.15$ \\
\hline Subscale 5 & $3.12 \pm 0.92$ & $2.91 \pm 1.093$ & $2.82 \pm 1.35$ & $2.54 \pm 1.35$ & $2.77 \pm 1.25$ \\
\hline Subscale 6 & $2.02 \pm 1.39$ & $1.60 \pm 1.23$ & $1.2 \pm 0.97$ & $1.27 \pm 1.14$ & $1.44 \pm 1.19$ \\
\hline Subscale 8 & $2.22 \pm 1.31$ & $2.29 \pm 1.14$ & $1.85 \pm 1.17$ & $1.96 \pm 1.24$ & $2.05 \pm 1.22$ \\
\hline Subscale 9 & $2.30 \pm 1.00$ & $1.98 \pm 0.92$ & $2.10 \pm 1.22$ & $1.81 \pm 1.17$ & $1.98 \pm 1.11$ \\
\hline Subscale 10 & $2.32 \pm 1.00$ & $1.33 \pm 0.87$ & $0.90 \pm 0.68$ & $1.02 \pm 0.81$ & $1.11 \pm 0.84$ \\
\hline Subscale 11 & $1.49 \pm 129$ & $1.17 \pm 1.37$ & $1.35 \pm 1.04$ & $1.04 \pm 1.07$ & $1.20 \pm 1.29$ \\
\hline Subscale 12 & $3.71 \pm 1.30$ & $3.32 \pm 1.47$ & $3.28 \pm 1.52$ & $3.12 \pm 1.57$ & $3.28 \pm 1.51$ \\
\hline
\end{tabular}




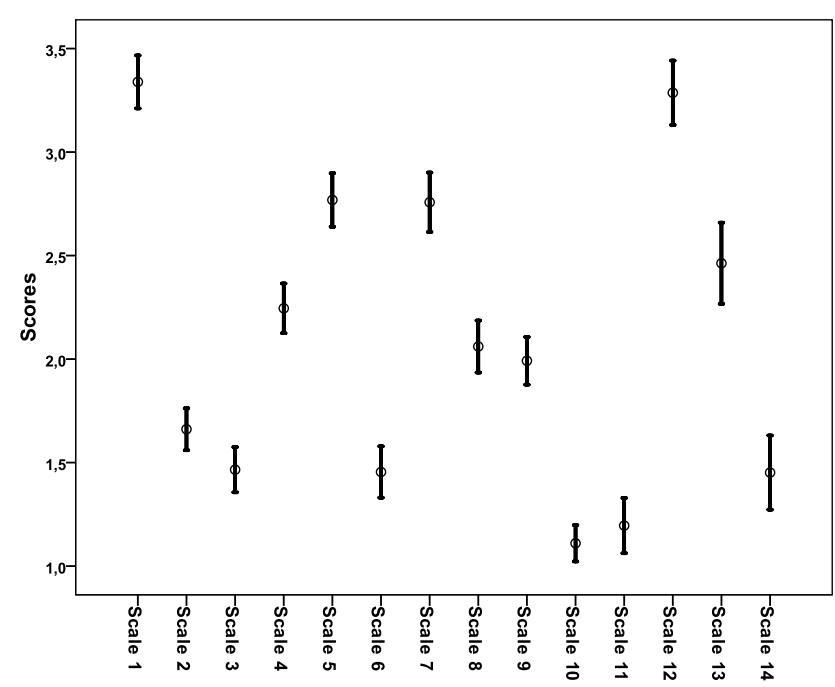

Figure 1. The scores in different subscales

\section{RESULTS}

Three hundred sixty three nurses in 7 cancer centers in 4 different cities in Turkey participated in the study. Median of work experience was 7 years ( 1 month - 35 years). While 147 (40.5\%) nurses had a more than 10 years of experience, $13.8 \%$ of them had less than 1 year of job experience in oncology. Total score of the study population was $29.2( \pm 10.4)$ out of 70 . The evaluation of scores in subscales showed that participants scored best in subscales 1 "general opinions and ideas about port catheters" and 12 "thoughts about the ideal port training". However, knowledge about subscales 2,3,10,11 and 14 were worse than others (Table 2, Figure 1).

The effects of the job experience on knowledge showed a negative correlation between them $(\mathrm{r}=-168, P=0.001)$. In addition, participants with an experience of more than 10 years had worse scores when compared with others $(27.2 \pm 11.4$ vs. 30.6 \pm 9.4 , $P=0.003$ ) (Table 2, Figure 2) The number of correct answers given to the theoretical questions was greater than that provided for clinical practice questions. In terms of the number of years of experience and subscale scores, a statistically significance difference was found for subscale $2(P=0.010)$, subscale $3(P<0.001)$, subscale $6(P=0.006)$, subscale $7(P=0.045)$, subscale $9(P=0.028)$, subscale $10(P=0.002)$, and total subscale score $(P=0.002)$. There was no significant difference between nurses working in university hospital and public hospital $(28.5 \pm 10.9$ vs. $30.4 \pm 10.4, P=0.086)$.

Table 3. Nurses' knowledge level and years of experience

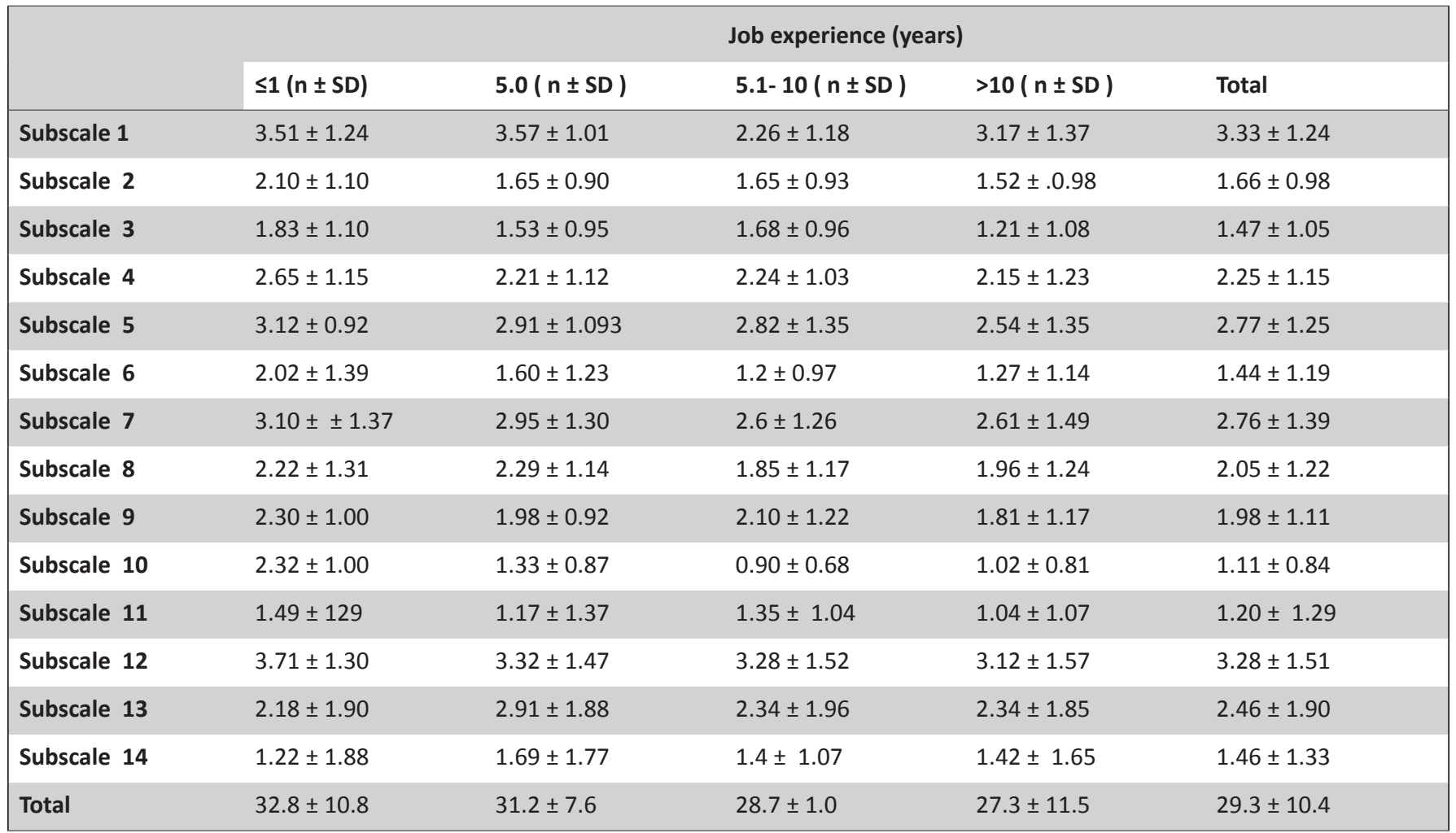




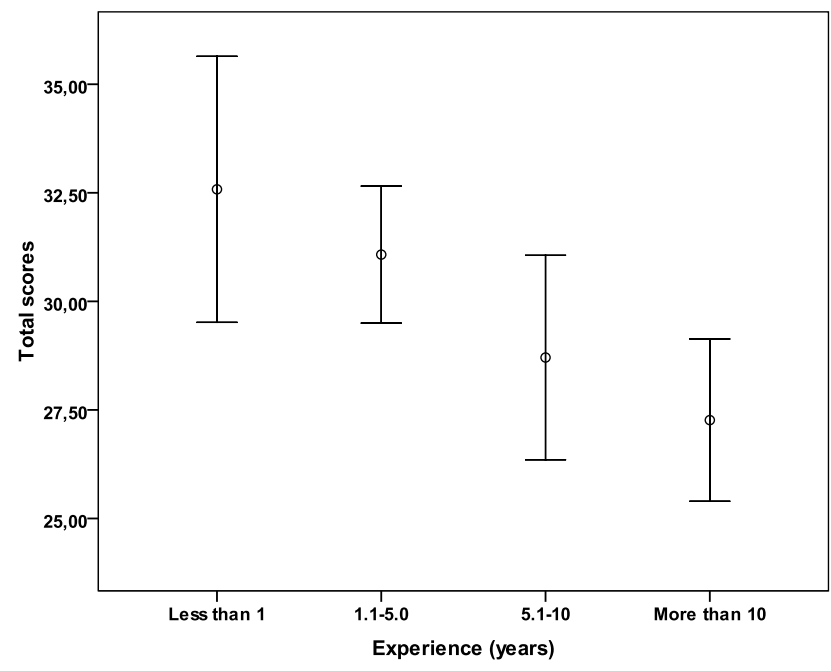

Figure 2. The association between total scores and level of job experience

\section{DISCUSSION}

In the present study, we aimed to investigate the nurses' level of knowledge about PCs in Turkey and to define the subjects in which more education strategies should be developed. To the best of our knowledge, our study is unique with its huge number of participants and its aim to define the subjects that should be emphasized during education sessions. Experience in the field was found to be negatively correlated with knowledge about PCs. In addition, complications of PCs and management strategies of them are subjects that should be discussed in the educational programs.

With advances in medicine and technology, many devices - especially implantable PCs - have been used for the treatment of oncology patients worldwide and also in Turkey (10). As a backbone of oncology team, nurses should try to incorporate new developments in their practices $[11,12]$. For this reason, nursing staff working in oncology field should be continuously educated. It has been shown that nurses participating training programs have more knowledge and practical skills than their counterparts $[13,14]$. The studies about nurses' knowledge levels have been conducted, but the findings are still limited.

In the literature, treatment outcomes have been associated with nurses' knowledge and years of experience in the field. In addition, nurses with more clinical experience have been suggested for better patient care $[15,16]$. Bakey et al. showed that there was no significant relationship between nurses' practice and their age, whereas there was a significant relationship between nurses' practice and their age in another study [5]. A different study also demonstrated that neither years of nursing experience nor age influenced the behaviors of nursing staff [17]. In our study, the total score of answers was $29.2( \pm 10.4)$ out of 70 . When compared with other studies, we found a worse level of knowledge in nurses working in oncology units. In addition, we found a negative correlation between nurses' knowledge level and years of work. Post graduation education is an important element of continuous well qualified patient care and studies concluded that nurses agree with the importance of education [18]. However, in most of the institutions in Turkey the education sessions are not regulated. In addition, health care workers are not obliged to attend to educational sessions legally. The results of our study pointed out the importance of post graduation education.

The studies conducted about PCs in oncology practice showed that nurses should be educated about where the implantable port catheter is placed, its period of use following implantation, the amount of normal saline to be used for washing the catheter, the special port needle, and the exchange time of these needles [1, 2]. Our study population was worse at complications of PCs and managing them.

There were some inevitable limitations of the study. The participants of the study were working at different institutions and their academic degree were not included in the analysis. In addition, institutional postgraduation education status was not evaluated. The number of patients daily cared (especially with PCs), working position (inpatient or outpatient clinic) could provide better analysis.

In conclusion, we found a low level of knowledge about PCs in nurses caring cancer patients. The study concluded that experience in the field is negatively correlated with knowledge about PCs. Nurses actively caring PCs should be routinely updated, especially about complications of PCs and management strategies of them. Better clinical strategies should be practiced to improve post graduation training of nurses.

Conflict of Interest: There is no conflict of interest.

Funding: The study has not been funded by any organization, group or society.

\section{REFERENCES}

1. Verity R, Wiseman T, Ream E, Teasdale E, Richardson A. Exploring the work of nurses who administer chemotherapy. Eur J Oncol Nurs. 2008; $12: 244-52$.

2. Ozden D, Caliskan N. Turkish nurses' level of knowledge regarding implantable port catheter care. Japan J Nurs Sci. 2012;9:1-8.

3. Camp-Sorrell D, editor State of the science of oncology vascular access devices. Seminars in oncology nursing, Elsevier, 2010.

4. Galloway M, editor Insertion and placement of central catheters in the oncology patient. Seminars in Oncology Nursing, Elsevier, 2010.

5. Bakey SJ. Evaluation of nurses' practices throughout hemodialysis treatment for patients in hemodialysis unit at Baghdad teaching hospitals. Kufa J Nurs Sci. 2014;2:23-7.

6. Linnemann B. Management of complications related to central venous catheters in cancer patients: an update. Semin Thromb Hemost. 2014;40:382-94.

7. Schiffer CA, Mangu PB, Wade JC, et al. Central venous catheter care for the patient with cancer: American Society of Clinical Oncology clinical practice guideline. J Clin Oncol. 2013;31:1357-70. 
8. Luciani A, Clement O, Halimi P, et al. Catheter-related upper extremity deep venous thrombosis in cancer patients: a prospective study based on Doppler US. Radiology. 2001;220:655-60.

9. McIlfatrick S, Sullivan K, McKenna H. Nursing the clinic vs. nursing the patient: nurses' experience of a day hospital chemotherapy service. J Clin Nurs. 2006;15(9):1170-8.

10. Özden D, Çalışkan N. Turkish nurses' level of knowledge regarding implantable port catheter care. Japan J Nurs Sci. 2012;9:1-8.

11. Gosselin TK, Dalton KA, Penne K, editors. The Role of the Advanced Practice Nurse in the Academic Setting. Seminars in Oncology Nursing, Elsevier, 2015.

12. Deshmukh M, Shinde M. Impact of structured education on knowledge and practice regarding venous access device care among nurses. Int J Sci Res (IJSR). 2014;3:895-901.

13. Matsubara MdGS, De Domenico EBL. Virtual learning environment in continuing education for nursing in oncology: an experimental study. $\mathrm{J}$ Cancer Education. 2015:1-7.
14. Beck S, Brant J, Donohue R, et al., editors. Oncology Nursing Certification: Relation to Nurses' Knowledge and Attitudes about Pain, Patient-Reported Pain Care Quality, and Pain Outcomes. Oncology Nursing Forum, 2016.

15. Zheng R-S, Guo Q-H, Dong F-Q, Owens RG. Chinese oncology nurses' experience on caring for dying patients who are on their final days: A qualitative study. Int J Nurs Studies. 2015;52:288-96.

16. Kreis H, Loehberg CR, Lux MP, et al. Patients' attitudes to totally implantable venous access port systems for gynecological or breast malignancies. Eur J Surg Oncol. 2007;33:39-43.

17. Yaakup H, Eng TC, Shah SA. Does Clinical experience help oncology nursing staff to deal with patient pain better than nurses from other displines? knowledge and attitudes survey amongst nurses in a tertiary care in Malaysia. Asian Pacific J Cancer Prev. 2014;15:4885-91.

18. Gibson F, Shipway L, Aldiss S, et al. Exploring the work of nurses who administer chemotherapy to children and young people. Eur J Oncol Nurs. 